\title{
Penentuan Faktor bagi Analisis Faktor Keberhasilan Proyek Preservasi Jalan Skema Long Segment
}

\author{
Factors Determination for Success Factor Analysis of Long Segment \\ Scheme Road Preservation Project
}

\author{
Ravinda Wahyu Kiranasari $^{1, a)}$, Ria Asih Aryani ${ }^{1, b)}$, Hitapriya Suprayitno ${ }^{1, c)}$ \& Herry \\ Budianto $^{1, \mathrm{~d})}$ \\ ${ }^{1)}$ Departemen Teknik Sipil, Institut Teknologi Sepulung November (ITS), Surabaya, Indonesia \\ Koresponden : ${ }^{a)}$ ravinda.kirana@gmail.com, ${ }^{b)}$ ria@ce.its.ac.id \& ${ }^{c)}$ suprayitno.hita@gmail.com
}

\begin{abstract}
ABSTRAK
Pelaksanaan proyek Preservasi Jalan Skema Long Segment masih mengalami kendala dalam pelaksanaannya, terlihat dari adanya pelaksanaan proyek yang mengalami sanksi denda keterlambatan, mutu konstruksi yang kurang baik, serta keterlambatan penyelesaian pekerjaan. Untuk menunjang kesuksesan pelaksanaan proyek di Balai Besar Pelaksanaan Jalan Nasional VIII, maka tujuan penelitian ini untuk mengetahui faktor penting bagi keberhasilan pelaksanaan Preservasi Jalan Skema Long Segment. Pengumpulan tingkat kepentingan faktor dilakukan dengan kuesioner dengan responden adalah manajerial pada BBPJN VIII, dan Kepala Satuan Kerja Wilayah Provinsi Jawa Timur yang pernah dan sedang terlibat menangani proyek Preservasi Jalan Skema Long Segment. Hasil penelitian menunjukkan terdapat 40 faktor yang dinilai penting dan dapat mempengaruhi keberhasilan pelaksanaan proyek. Faktor tersebut dikategorikan berdasarkan tingkat kepentingan, yaitu : 15 faktor dinilai sangat penting, 24 faktor dinilai penting, dan 1 faktor dinilai cukup penting.
\end{abstract}

Kata Kunci : manajemen infrastruktur, faktor keberhasilan, proyek konstruksi, preservasi jalan skema long segment.

\section{PENDAHULUAN}

Prinsip dasar manajemen aset infrastruktur merupakan tugas, pengetahuan dan sains untuk mengelola infrastruktur selama umur siklus hidupnya agar infrastruktur dapat berfungsi secara efektif, efisien, dan berkelanjutan (Suprayitno \& Soemitro, 2018). Untuk menjalankan prinsip dasar manajemen aset tersebut, Direktur Jenderal Bina Marga Kementerian Pekerjaan Umum dan Perumahan Rakyat menerapkan program Preservasi Jalan. Direktorat Jenderal Bina Marga sebagai penyelenggara perumusan dan pelaksanaan kebijakan di bidang penyelenggaraan jalan memberlakukan skema pemeliharaan jalan sesuai Surat Edaran Direktur Jenderal Bina Marga Nomor 01/SE/Db/2019 yaitu Preservasi Jalan Skema Long Segment. Preservasi Jalan Skema Long Segment yaitu penanganan preservasi jalan dalam batasan satu panjang segment yang menerus (bisa lebih dari satu ruas) yang dilaksanakan dengan tujuan untuk mendapatkan kondisi jalan yang seragam yaitu jalan mantap dan standar sepanjang segment. Sistim Preservasi Jalan dengan Skema Long Segment merupakan upaya dalam peningkatan performa jalan, dimana pemeliharaan jalan berbasis kinerja agar memenuhi tingkat layanan Jalan. Upaya Direktorat Jenderal Bina Marga memberlakukan Pemeliharaan Jalan Skema Long Segment bertujuan untuk meningkatkan kinerja pelaku pemeliharaan jalan agar mencapai target nasional kemantapan jalan. Pelaksanaan proyek Preservasi Jalan Skema Long Segment masih mengalami kendala dalam pelaksanaannya, terlihat dari adanya pelaksanaan 
proyek yang mengalami sanksi denda keterlambatan, mutu konstruksi yang kurang baik, serta keterlambatan penyelesaian pekerjaan.

Dilihat masih terdapat permasalahan dalam pelaksanaannya, maka diperlukan penentuan faktor bagi analisis faktor yang yang mempengaruhi keberhasilan Kontrak Preservasi Jalan Skema Long Segment. Faktor keberhasilan tersebut jika dipenuhi dalam pelaksanaan Kontrak Preservasi Jalan Skema Long Segment akan berpengaruh dalam keberhasilan pelaksanaan proyek dilihat dari indikator biaya, mutu, dan waktu pelaksanaan serta diharapkan dapat memenuhi keberhasilan pencapaian kemantapan jalan.

\section{METODE PENELITIAN}

Penelitian tentang Penentuan tingkat kepentingan faktor bagi analisis faktor keberhasilan proyek Preservasi Jalan Skema Long Segment menggunakan alur berfikir sebagai berikut: penentuan latar belakang, penentuan tujuan, penentuan metode, pengumpulan data, melakukan analisis, dan diakhiri dengan kesimpulan. Sesuai dengan tujuan penentuan faktor awal keberhasilan pelaksanaan Preservasi Jalan Skema Long Segment, maka sifat identifikasi ditujukan untuk mengumpulan faktor - faktor yang berpengaruh dalam keberhasilan pelaksanaan yang terdiri dari faktor yang ada pada pihak Kontraktor, pihak Pejabat Pembuat Komitmen (PPK), dan pihak Konsultan Pengawas.

\section{PENGUMPULAN DATA}

\section{Prinsip Dasar Analisis}

Hasil identifikasi faktor dapat digunakan bagi Analisis Faktor Keberhasilan Preservasi Jalan Skema Long Segment. Faktor adalah sesuatu yang dapat mempengaruhi kinerja (Suprayitno, Soemitro, Maulana, \& Hesna, 2019). Kinerja dapat terdiri dari beberapa komponen. Setiap komponen kinerja menunjukkan kualitas berbeda. Dengan demikian analisis dimulai dengan identifikasi faktor keberhasilan yang ada pada pihak - pihak terkait, yaitu pihak Kontraktor, pihak PPK, dan Pihak Konsultan Pengawas yang digambarkan pada Gambar 1.

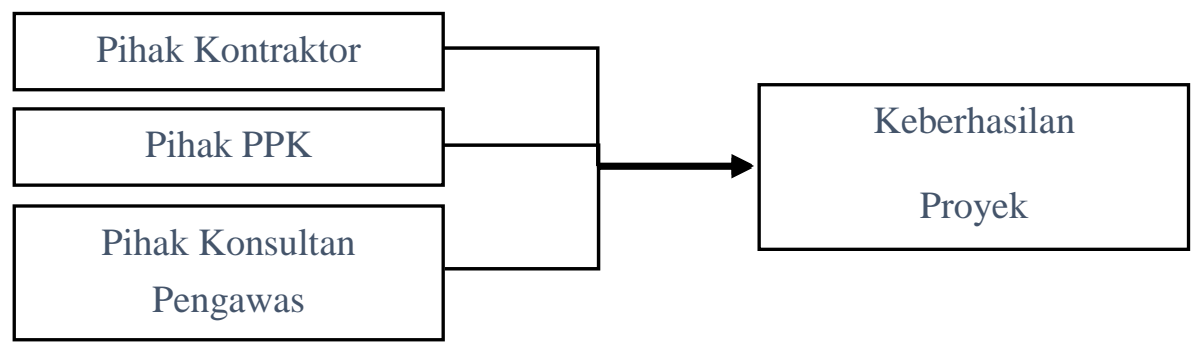

Gambar 1. Pihak yang Mempengaruhi Keberhasilan

Identifikasi faktor yang ada pada pihak Kontraktor yang dapat dilihat dari aspek Sumber daya Manusia (SDM), Manajemen Kerja, Material, Peralatan utama, dan Pendanaan, kemudian pihak PPK yang dapat dilihat dari aspek Sumber daya Manusia (SDM), manajemen kerja, dan pendanaan, dan pihak Konsultan Pengawas yang dapat dilihat dari aspek Sumber daya Manusia (SDM), dan manajemen kerja yang telah digambarkan pada Gambar 2. Masing - masing aspek terdapat beberapa faktor yang akan divalidali oleh pakar yang mengetahui dan pernah menangani pelaksanaan kontrak Preservasi Jalan Skema Long Segment. Dalam validasi faktor ini akan terlihat tingkat kepentingan tiap - tiap faktor dalam mempengaruhi keberhasilan pelaksanaan proyek. Keberhasilan pelaksanaan proyek dalam penelitian ini dilihat dari indikator biaya, mutu, dan waktu. Keberhasilan indikator biaya dapat dilihat dari adanya pemotongan sanksi pembayaran dari ketidak tercapainya standar kinerja jalan. Keberhasilan indikator mutu dapat dilihat dari adanya cacat mutu dalam pelaksanaan proyek yang dapat 
diselesaikan oleh Kontraktor. Keberhasilan indikator waktu dilihat dari adanya keterlambatan pelaksanaan pada setiap lingkup pekerjaan.

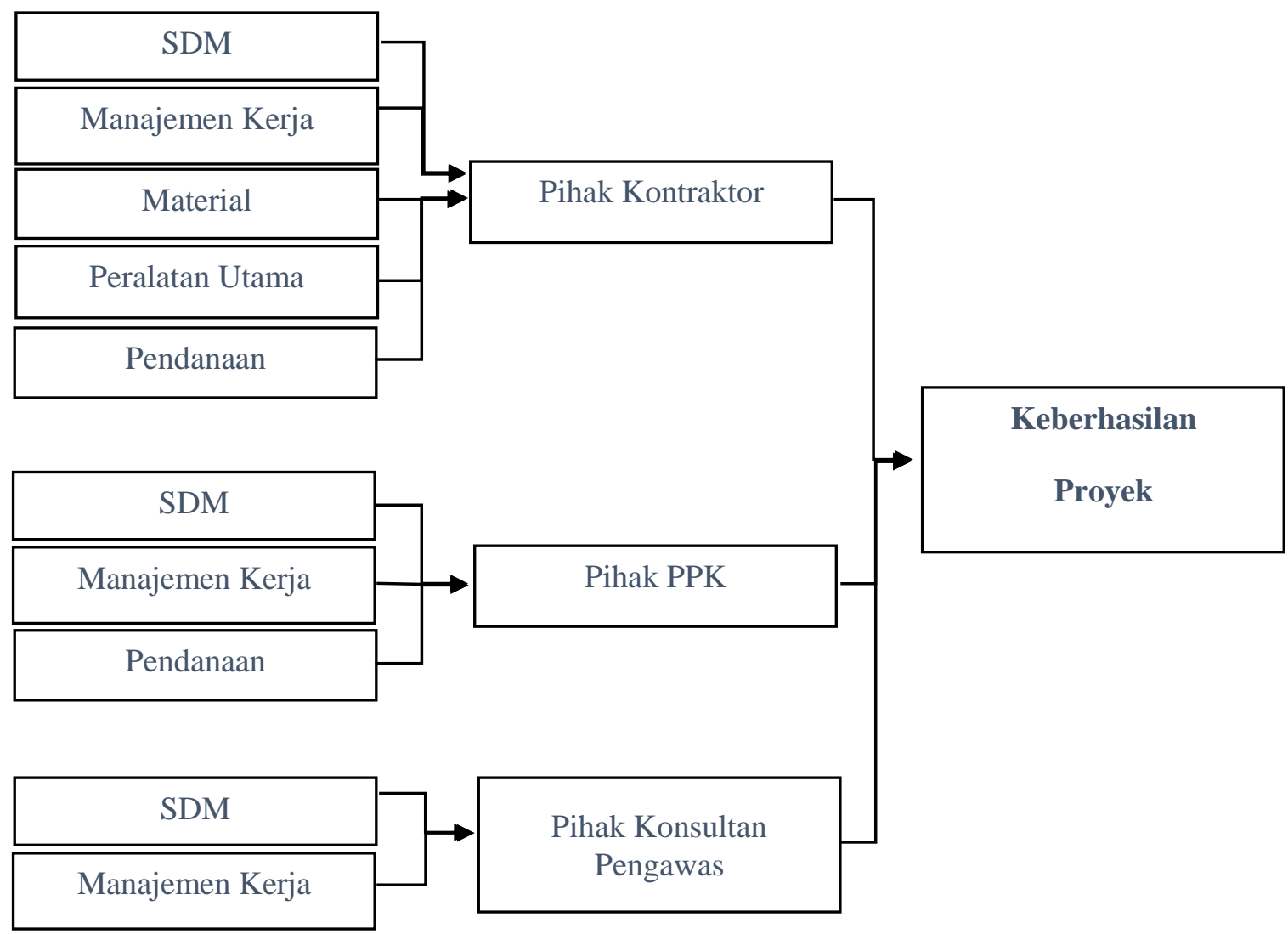

Gambar 2. Skema Faktor Keberhasilan

\section{Identifikasi Faktor Keberhasilan}

Berdasarkan beberapa literatur (Budilukito \& Mulyono 2016; Sita \& Mulyono 2016; Zachawerus \& Soekiman 2018; Iek 2019; Khaqiqi \& Wulandari 2019) yang didapat, terdapat beberapa faktor yang mempengaruhi keberhasilan proyek. Pada langkah identifikasi ini, dikumpulkan 40 faktor yang dinilai dapat mempengaruhi keberhasilan pelaksanaan kontrak dengan indikator keberhasilan biaya, mutu, dan waktu. Tabel 1 merupakan variabel faktor yang akan digunakan pada penelitian ini. Identifikasi faktor dikategorikan menurut faktor yangada pada masing - masing pihak, yang selanjutnya dikelompokkan menurut aspek yang ada pada pihak tersebut. 
Tabel 1. Faktor yang Mempengaruhi Keberhasilan Pelaksanaan Kontrak

\begin{tabular}{|c|c|c|c|c|}
\hline No & $\begin{array}{c}\text { Pihak } \\
\text { Terkait }\end{array}$ & Aspek & Var & Faktor \\
\hline 1 & \multirow{19}{*}{ Kontraktor } & \multirow{7}{*}{ SDM } & T1 & Pengalaman Kontraktor \\
\hline 2 & & & $\mathrm{~T} 2$ & Jumlah SDM Kontraktor \\
\hline 3 & & & T3 & Sertifikasi keahlian Kontraktor \\
\hline 4 & & & T4 & Kepatuhan Kontraktor terhadap mutu \\
\hline 5 & & & T5 & $\begin{array}{l}\text { Kepatuhan Kontraktor untuk mencapai standar kinerja jalan } \\
\text { untuk memenuhi tingkat layanan seluruh bagian-bagian jalan }\end{array}$ \\
\hline 6 & & & T6 & Kemampuan keahlian teknis Kontraktor \\
\hline 7 & & & $\mathrm{~T} 7$ & Adaptasi kontraktor terhadap perubahan/addendum kontrak \\
\hline 8 & & \multirow{3}{*}{$\begin{array}{l}\text { Manajemen } \\
\text { Kerja }\end{array}$} & $\mathrm{T} 8$ & $\begin{array}{l}\text { Kesesuaian metode kerja Kontraktor terhadap penerapan } \\
\text { standar mutu }\end{array}$ \\
\hline 9 & & & T9 & $\begin{array}{l}\text { Kesesuaian metode kerja Kontraktor terhadap karakteristik } \\
\text { material }\end{array}$ \\
\hline 10 & & & $\mathrm{~T} 10$ & $\begin{array}{l}\text { Kesesuaian metode kerja Kontraktor terhadap kondisi } \\
\text { lingkungan }\end{array}$ \\
\hline 11 & & \multirow{3}{*}{ Material } & T11 & Ketepatan mutu material \\
\hline 12 & & & T12 & Ketersediaan volume material \\
\hline 13 & & & $\mathrm{~T} 13$ & Ketepatan waktu pengiriman material \\
\hline 14 & & \multirow{5}{*}{$\begin{array}{l}\text { Peralatan } \\
\text { Utama }\end{array}$} & T14 & Kelaikan fungsi peralatan utama \\
\hline 15 & & & $\mathrm{~T} 15$ & Ketepatan spesifikasi teknis peralatan utama \\
\hline 16 & & & T16 & Jumlah ketersediaan peralatan utama \\
\hline 17 & & & T17 & Kepemilikan peralatan utama \\
\hline 18 & & & T18 & Kebaruan teknologi peralatan utama \\
\hline 19 & & Pendanaan & T19 & Ketersediaan dana (cash flow) Kontraktor \\
\hline 20 & \multirow{12}{*}{ PPK } & \multirow{7}{*}{ SDM } & $\mathrm{P} 1$ & Pengalaman manajerial PPK \\
\hline 21 & & & $\mathrm{P} 2$ & Sertifikat manajerial PPK \\
\hline 22 & & & P3 & Responsif PPK terhadap urgensi perbaikan kontrak \\
\hline 23 & & & P4 & $\begin{array}{l}\text { Kemampuan PPK mengarahkan pelaksanaan konstruksi untuk } \\
\text { memenuhi tingkat layanan seluruh bagian - bagian jalan }\end{array}$ \\
\hline 24 & & & P5 & Kemampuan PPK dalam pengendalian administrasi kontrak \\
\hline 25 & & & P6 & $\begin{array}{l}\text { Kemampuan PPK dalam pengendalian ketentuan teknis } \\
\text { pelaksanaan pekerjaan }\end{array}$ \\
\hline 26 & & & $\mathrm{P} 7$ & Penguasaan PPK terhadap kondisi lapangan \\
\hline 27 & & \multirow{4}{*}{$\begin{array}{l}\text { Manajemen } \\
\text { Kerja }\end{array}$} & P8 & $\begin{array}{l}\text { Pengendalian PPK terhadap Kontraktor dan Konsultan } \\
\text { pengawas }\end{array}$ \\
\hline 28 & & & P9 & Pengendalian PPK terhadap mutu konstruksi \\
\hline 29 & & & $\mathrm{P} 10$ & Pengendalian PPK terhadap waktu pelaksanaan \\
\hline 30 & & & P11 & Pengendalian PPK terhadap biaya pelaksanaan \\
\hline 31 & & Pendanaan & P12 & Ketersediaan anggaran DIPA \\
\hline 32 & \multirow{9}{*}{$\begin{array}{l}\text { Konsultan } \\
\text { Pengawas }\end{array}$} & \multirow{7}{*}{ SDM } & K1 & Sertifikat keahlian Konsultan Pengawas \\
\hline 33 & & & $\mathrm{~K} 2$ & Kemampuan keahlian teknis tim Konsultan pengawas \\
\hline 34 & & & K3 & Pengalaman Konsultan Pengawas \\
\hline 35 & & & K4 & Jumlah tenaga ahli Konsultan Pengawas \\
\hline 36 & & & K5 & Adaptasi Konsultan Pengawas pada perubahan kontrak \\
\hline 37 & & & K6 & $\begin{array}{l}\text { Kepatuhan Konsultan Pengawas terhadap standar mutu, } \\
\text { waktu, biaya, dan dokumen kontrak }\end{array}$ \\
\hline 38 & & & K7 & $\begin{array}{l}\text { Pemahaman Konsultan pengawas terhadap teknologi bahan } \\
\text { dan peralatan utama }\end{array}$ \\
\hline 39 & & \multirow{2}{*}{$\begin{array}{l}\text { Manajemen } \\
\text { Kerja }\end{array}$} & K8 & Kesesuaian mekanisme kontrol konsultan pengawas \\
\hline 40 & & & K9 & Implementasi program mutu Konsultan yang efektif \\
\hline
\end{tabular}




\section{Instrumen Penelitian}

Alat pengumpulan data pada penelitian ini menggunakan metode kuesioner. Kuesioner merupakan teknik pengumpulan data yang dilakukan dengan cara memberi seperangkat pertanyaan atau pernyataan tertulis kepada responden untuk dijawabnya (Sugiyono, 2017). Penelitian ini menggunakan teknik Non-probability Sampling, yaitu teknik pengambilan sampel yang tidak memberi peluang atau kesempatan sama bagi setiap unsur atau anggota populasi untuk dipilih menjadi sampel (Sugiyono, 2017), dengan teknik Purposive sampling atau teknik penentuan sampel dengan pertimbangan tertentu. Responden pada penelitian ini merupakan manajerial pada Balai Besar Pelaksanaan Jalan Nasional VIII Surabaya dan merupakan pakar jalan yang pernah menangani proyek Preservasi Jalan Skema Long Segment. Tabel 2 berikut merupakan responden dalam penelitian ini.

Tabel 2. Responden Penelitian

\begin{tabular}{|c|l|c|}
\hline No & \multicolumn{1}{|c|}{ Responden } & Jumlah Responden \\
\hline 1 & Kepala Bidang Preservasi dan Peralatan I & 1 \\
\hline 2 & Kepala Bidang Preservasi dan Peralatan II & 1 \\
\hline 3 & Kepala Seksi Preservasi dan Peralatan I & 1 \\
\hline 4 & Kepala Seksi Preservasi dan Peralatan II & 1 \\
\hline 5 & Kepala Satuan Kerja & 5 \\
\hline & Jumlah Sampel & $\mathbf{9}$ \\
\hline
\end{tabular}

\section{ANALISIS PENELITIAN}

\section{Metode Analisis}

Metode analisis data yang digunakan pada penelitian ini adalah metode deskriptif. Metode deskriptif adalah metode yang digunakan untuk mencari unsur-unsur, ciri-ciri, sifatsifat suatu fenomena (Suryana, 2010). Penilaian tingkat pengaruh faktor terhadap keberhasilan pelaksanaan proyek diukur menggunakan skala likert. Skala likert yang dalam penelitian ini menggunakan skala 4 kepentingan. Dalam pemilihan skala yang digunakan, peneliti memilih skala 4 untuk mengakomodasi tingkat kepentingan faktor yang akan dinilai oleh responden. Nilai 4 untuk menilai faktor dengan tingkat sangat penting, nilai 3 untuk menilai faktor dengan tingkat penting, nilai 2 untuk menilai faktor dengan tingkat cukup, dan nilai 1 untuk menilai faktor dengan tingkat tidak penting. Dalam skala penelitian ini tidak menggunakan nilai 5 yaitu sangat tidak penting karena dianggap minimal kategori tidak penting sudah dapat mengeliminasi faktor tersebut.

\section{Analisis Data}

Analisis data untuk mengetahui tingkat kepentingan faktor pada penelitian ini menggunakan jumlah nilai dari pendapat responden pada masing - masing faktor. Dengan asumsi semakin besar nilai penjumlahan faktor maka semakin besar tingkat kepentingan faktor tersebut terhadap keberhasilan pelaksanaan proyek. Tabel 3 merupakan penentuan kriteria penilaian tingkat kepentingan faktor.

Tabel 3. Penentuan Kriteria Penilaian dan Rentang Nilai

\begin{tabular}{|c|c|}
\hline Rentang Nilai & Kriteria Penilaian \\
\hline $28-36$ & Sangat Penting \\
\hline $19-27$ & Penting \\
\hline $10-18$ & Cukup \\
\hline $1-9$ & Tidak Penting \\
\hline
\end{tabular}


Tabel 4. Tingkat Kepentingan Faktor Menurut Hasil Kuesioner Pakar

\begin{tabular}{|c|c|c|c|}
\hline Kepentingan & Pihak & Faktor & Nilai \\
\hline \multirow{15}{*}{$\begin{array}{l}\text { Sangat } \\
\text { Penting }\end{array}$} & \multirow{7}{*}{ Kontraktor } & Kelaikan fungsi peralatan utama & 35 \\
\hline & & Kepatuhan Kontraktor terhadap mutu & 33 \\
\hline & & $\begin{array}{l}\text { Kesesuai metode kerja Kontraktor terhadap penerapan standar } \\
\text { mutu }\end{array}$ & 33 \\
\hline & & Ketepatan mutu material & 33 \\
\hline & & Ketersediaan volume material & 33 \\
\hline & & Ketepatan spesifikasi teknis peralatan utama & 33 \\
\hline & & ketersediaan dana (cash flow) Kontraktor & 33 \\
\hline & \multirow{6}{*}{ PPK } & Pengendalian PPK terhadap biaya pelaksanaan & 34 \\
\hline & & Pengendalian PPK terhadap mutu konstruksi & 34 \\
\hline & & Kemampuan PPK dalam pengendalian administrasi kontrak & 33 \\
\hline & & $\begin{array}{l}\text { Kemampuan PPK dalam pengendalian ketentuan teknis } \\
\text { pelaksanaan pekerjaan }\end{array}$ & 33 \\
\hline & & Pengendalian terhadap waktu pelaksanaan oleh PPK & 33 \\
\hline & & Ketersediaan anggaran DIPA & 33 \\
\hline & \multirow{2}{*}{$\begin{array}{l}\text { Konsultan } \\
\text { Pengawas }\end{array}$} & $\begin{array}{l}\text { Kepatuhan Konsultan Pengawas terhadap standar mutu, } \\
\text { waktu, biaya, dan dokumen kontrak }\end{array}$ & 31 \\
\hline & & $\begin{array}{l}\text { Implementasi program mutu Konsultan pengawas yang } \\
\text { efektif }\end{array}$ & 31 \\
\hline \multirow{24}{*}{ Penting } & \multirow{11}{*}{ Kontraktor } & $\begin{array}{l}\text { Kesesuaian metode kerja Kontraktor terhadap karakteristik } \\
\text { material }\end{array}$ & 25 \\
\hline & & $\begin{array}{l}\text { Kepatuhan untuk mencapai standar kinerja jalan untuk } \\
\text { memenuhi tingkat layanan seluruh bagian-bagian jalan }\end{array}$ & 25 \\
\hline & & Jumlah ketersediaan peralatan utama & 24 \\
\hline & & $\begin{array}{l}\text { Kesesuaian metode kerja Kontraktor terhadap kondisi } \\
\text { lingkungan }\end{array}$ & 24 \\
\hline & & Ketepatan waktu pengiriman material & 24 \\
\hline & & Kemampuan keahlian teknis Kontraktor & 23 \\
\hline & & Adaptasi kontraktor terhadap perubahan /addendum kontrak & 23 \\
\hline & & Kepemilikan peralatan utama & 23 \\
\hline & & Pengalaman Kontraktor & 22 \\
\hline & & Sertifikasi keahlian Kontraktor & 22 \\
\hline & & Jumlah SDM Kontraktor & 22 \\
\hline & \multirow{6}{*}{ PPK } & Penguasaan PPK terhadap kondisi lapangan & 27 \\
\hline & & $\begin{array}{l}\text { Pengendalian oleh PPK terhadap kontraktor pelaksanaan dan } \\
\text { konsultan pengawas }\end{array}$ & 26 \\
\hline & & $\begin{array}{l}\text { Kemampuan PPK mengarahkan pelaksanaan konstruksi untuk } \\
\text { memenuhi tingkat layanan seluruh bagian - bagian jalan }\end{array}$ & 25 \\
\hline & & Responsif PPK terhadap urgensi perbaikan kontrak & 23 \\
\hline & & Pengalaman manajerial PPK & 23 \\
\hline & & Sertifikat manajerial PPK & 22 \\
\hline & \multirow{7}{*}{$\begin{array}{l}\text { Konsultan } \\
\text { Pengawas }\end{array}$} & Kemampuan keahlian teknis tim Konsultan pengawas & 27 \\
\hline & & Kesesuaian mekanisme kontrol konsultan pengawas & 25 \\
\hline & & Pengalaman Konsultan Pengawas & 23 \\
\hline & & Adaptasi Konsultan Pengawas pada perubahan kontrak & 23 \\
\hline & & $\begin{array}{l}\text { Pemahaman Konsultan pengawas terhadap teknologi bahan } \\
\text { dan peralatan utama }\end{array}$ & 23 \\
\hline & & Jumlah tenaga ahli Konsultan Pengawas & 22 \\
\hline & & Sertifikat keahlian Konsultan Pengawas & 22 \\
\hline Cukup & Kontraktor & Kebaruan teknologi peralatan utama & 14 \\
\hline
\end{tabular}


Pada Tabel 4 disampaikan faktor yang dinilai pakar berpengaruh dalam keberhasilan pelaksanaan Kontrak Preservasi Jalan Skema Long Segment di karegorikan dalam tingkat kepentingan dan diurutkan berdasarkan perolehan nilai kepentingan.

Faktor dengan kategori sangat penting pada pihak Kontraktor merupakan faktor - fakor pada Kontraktor yang dinilai sangat mempengaruhi keberhasilan pelaksanaan kontrak, yaitu :

1. Faktor kelaikan fungsi peralatan utama dinilai sangat penting, karena kelaikan fungsi peralatan utama berperan sangat penting dalam pelaksanaan preservasi jalan. Ketidak laikan peralatan utama dapat menimbulkan keterlambatan pelaksanaan.

2. Faktor kepatuhan Kontraktor terhadap mutu dinilai sangat penting, karena kepatuhan terhadap standar mutu dalam setiap pelaksanaan pekerjaan, dapat menghasilkan mutu konstruksi yang handal serta memenuhi tingkat layanan seluruh bagian-bagian jalan. Dalam pelaksanaan proyek konstruksi terdapat dokumen RMP (Rencana Mutu Pelaksanaan) yang disusun oleh PPK dan RMK (Rencana Mutu Kontrak) yang disusun oleh Kontraktor sebagai alat kontrol agar tercapai mutu yang sesuai dengan persyaratan kontrak.

3. Faktor kesesuai metode kerja Kontraktor terhadap penerapan standar mutu dinilai sangat penting, karena penentuan metode kerja yang akan digunakan akan mempengaruhi mutu kontruksi yang akan dihasilkan.

4. Faktor ketepatan mutu material dinilai sangat penting, karena tingkat ketepatan spesifikasi material dapat mempengaruhi hasil pekerjaan yang dihasilkan.

5. Faktor ketersediaan volume material dinilai sangat penting, karena tingkat ketersediaan volume material dilapangan menentukan ketepatan waktu pelaksanaan pekerjaan.

6. Faktor ketepatan spesifikasi teknis peralatan utama dinilai sangat penting, karena ketepatan spesifikasi teknis peralatan utama berhubungan dengan kapasitas, jenis, dan fungsi peralatan utama yang dibutuhkan dalam pelaksanaan proyek tersebut.

7. Faktor ketersediaan dana (cash flow) Kontraktor dinilai sangat penting, karena ketersediaan dana mempengaruhi pembelian material dan operasional yang dibutuhkan pelaksanaan proyek.

Faktor dengan kategori sangat penting pada pihak PPK merupakan faktor - fakor pada PPK yang dinilai sangat mempengaruhi keberhasilan pelaksanaan kontrak, yaitu :

1. Faktor pengendalian PPK terhadap biaya pelaksanaan dinilai sangat penting, karena tingkat pengendalian terhadap biaya proyek seperti pembalian material sesuai harga satuan, pencairan dana proyek, realisasi anggaran proyek, dan pemberlakuan sanksi potongan pembayaran maupun denda keterlambatan sehingga dana yang digunakan sesuai dengan rencana dalam kontrak.

2. Faktor pengendalian PPK terhadap mutu konstruksi dinilai sangat penting, karena tingkat intensitas pengendalian mutu dengan monitoring lapangan dan tes lab dapat mengendalikan mutu konstruksi sesuai standar dokumen mutu.

3. Faktor kemampuan PPK dalam pengendalian administrasi kontrak dinilai sangat penting, karena tingkat kemampuan PPK taat administrasi dalam pelaksanaan kontrak dapat mengontrol pelaksanaan sesuai kontrak. Seperti mengendalikan pelaksanaan sesuai jadwal, melakukan sanksi apabila ada pelaksanaan yang tidak sesuai.

4. Faktor kemampuan PPK dalam pengendalian ketentuan teknis pelaksanaan pekerjaan dinilai sangat penting, karena tingkat kemampuan PPK dalam mengendalikan pelaksanaan proyek sesuai dengan ketentuan spesifikasi teknis akan menghasilkan mutu konstruksi yang baik.

5. Faktor pengendalian terhadap waktu pelaksanaan oleh PPK dinilai sangat penting, karena tingkat pengendalian pelaksanaan dengan jadwal dalam kontrak dapat mengontrol adanya keterlambatan pelaksanaan. 
6. Faktor ketersediaan anggaran dinilai sangat penting, karena ketersediaan anggaran pada DIPA (Daftar Isian Pelaksanaan Anggaran) sesuai dengan kebutuhan proyek mempengaruhi kelancaran pembayaran kepada Kontraktor.

Faktor dengan kategori sangat penting pada pihak Konsultan Pengawas merupakan faktor - fakor pada Konsultan Pengawas yang dinilai sangat mempengaruhi keberhasilan pelaksanaan kontrak, yaitu :

1. Faktor kepatuhan Konsultan pengawas terhadap standar mutu, waktu, biaya, dan dokumen kontrak dinilai sangat penting. Tingkat kepatuhan dan kompentensi Konsultan Pengawas terhadap mutu, waktu, biaya, dan dokumen kontrak diharapkan Konsultan dapat memonitoring hasil pekerjaan Kontraktor apakah sesuai dengan standar mutu, jadwal pelaksanaan, dan biaya sesuai dokumen kontrak.

2. Faktor implementasi program mutu Konsultan pengawas yang efektif dinilai sangat penting, karena dalam pelaksanaan pengawasan konsultan selalu berpedoman pada dokumen mutu.

Faktor dengan kategori penting pada pihak Kontraktor merupakan faktor - fakor pada Kontraktor yang dinilai mempengaruhi keberhasilan pelaksanaan kontrak, yaitu :

1. Faktor kepatuhan untuk mencapai standar kinerja jalan untuk memenuhi tingkat layanan seluruh bagian-bagian jalan dinilai oleh pakar sebagai faktor dengan kriteria penting, karena dinilai kepatuhan untuk mencapai standar kinerja sesuai dengan kontrak akan menghasilkan mutu konstruksi yang baik serta pemenuhan tingkat layanan seluruh bagian jalan.

2. Faktor kesesuaian metode kerja terhadap karakteristik material dinilai penting, karena metode kerja yang digunakan harus disesuaian dengan karakteristik material yang digunakan untuk menghasilkan konstruksi yang handal.

3. Faktor jumlah ketersediaan peralatan utama dinilai penting, karena kesesuaian ketersediaan jumlah peralatan utama dapat memperlancar pelaksanaan konstruksi.

4. Faktor kesesuaian metode kerja Kontraktor terhadap kondisi lingkungan dinilai penting. Ketepatan pemilihan metode kerja terhadap kondisi lingkungan mempengaruhi hasil mutu konstruksi, sehingga mempengaruhi pemenuhan tingkat layanan seluruh bagian jalan.

5. Faktor ketepatan waktu pengiriman material dinilai penting, karena tingkat ketepatan waktu pengiriman material berpengaruh pada ketersediaan material untuk pelaksanaan pekerjaan sehingga pelaksanaan sesuai dengan jadwal.

6. Faktor kemampuan keahlian teknis Kontraktor dinilai penting, karena kemampuan keahlian teknis Kontraktor menentukan bagaimana kontraktor melaksanakan pekerjaan sesuai spesifikasi teknis.

7. Faktor adaptasi kontraktor terhadap perubahan/addendum kontrak dinilai penting, karena semakin cepat melaksanakan pekerjaan sesuai dengan addendum kontrak, pelaksanaan pekerjaan dapat selesai sesuai addendum kontrak yang berlaku.

8. Faktor kepemilikan peralatan utama dinilai penting, karena tingkat kepemilikan peralatan utama mempengaruhi ketepatan waktu ketersediaan peralatan utama yang akan dipakai dalam pelaksanaan.

9. Faktor pengalaman Kontraktor dalam pelaksanaan proyek dinilai penting, karena diharapkan semakin banyak pengalaman mengerjakan proyek konstruksi maka semakin mengetahui detail pelaksanaan.

10. Faktor kepatuhan Kontraktor untuk mencapai standar kinerja jalan untuk memenuhi tingkat layanan seluruh bagian-bagian jalan dinilai penting, karena tingkat kepatuhan Kontraktor terhadap pencapaian standar kinerja jalan berpengaruh terhadap mutu konstruksi dalam pemenuhan tingkat layanan seluruh bagian jalan dan dapat 
diberlakukan pemotongan sanksi pembayaran apabila tidak mencapai standar kinerja jalan yang ditetapkan.

11. Faktor sertifikasi keahlian Kontraktor dinilai penting, karena kesesuaian sertifikasi keahlian dapat mengetahui detail pelaksanaan pekerjaan dilapangan sesuai dengan spesifikasi teknis.

12. Faktor jumlah SDM Kontraktor dinilai penting. Ketepatan jumlah SDM dapat mengoptimalkan pekerjaan sesuai dengan jadwal penyelesaian pekerjaan.

Faktor dengan kategori penting pada pihak PPK merupakan faktor - fakor pada PPK yang dinilai mempengaruhi keberhasilan pelaksanaan kontrak, yaitu :

1. Faktor penguasaan PPK terhadap kondisi lapangan dinilai penting, karena tingkat penguasaan PPK terhadap kondisi lapangan seperti daerah rawan bencana, kondisi jalan yang cepat rusak, atau jalur transportasi dengan beban berat, dapat mengetahui penanganan apa yang seharusnya dilakukan.

2. Faktor pengendalian PPK terhadap kontraktor pelaksanaan dan konsultan pengawas dinilai penting, karena tingkat pengendalian kontraktor dan konsultan pengawas terhadap proyek dapat mendeteksi adanya permasalahan dalam pelaksanaan. Pengendalian dapat berupa monitoring lapangan, laporan mingguan, dan monitoring dokumen administrasi pelaksanaan.

3. Faktor kemampuan PPK mengarahkan pelaksanaan konstruksi untuk memenuhi tingkat layanan seluruh bagian-bagian jalan dinilai penting, karena kemampuan PPK mengarahkan pelaksanaan proyek sesuai dokumen kontrak dapat menghasilkan pekerjaan yang tepat mutu, tepat waktu, dan tepat biaya serta memenuhi tingkat layanan seluruh bagian-bagian jalan.

4. Faktor responsif PPK terhadap urgensi perbaikan kontrak dinilai penting. Tingkat responsif PPK terhadap penyelesaian perbaikan/addendum kontrak dapat mempercepat pekerjaan sesuai dengan detail pekerjaan pada dokumen perbaikan kontrak.

5. Faktor pengalaman manajerial PPK dinilai penting. Tingkat pengalaman PPK diharapkan semakin banyak proyek konstruksi yang pernah dikelola, semakin dapat memahami pelaksanaan sesuai dalam kontrak.

6. Faktor sertifikat manajerial PPK dinilai penting. Tingkat frekuensi pelatihan sertifikasi manajerial oleh PPK dinilai penting karena meningkatkan wawasan manajerial konstruksi jalan.

Faktor dengan kategori penting pada pihak Konsultan Pengawas merupakan faktor fakor pada Konsultan Pengawas yang dinilai mempengaruhi keberhasilan pelaksanaan kontrak, yaitu :

1. Faktor kemampuan keahlian teknis tim Konsultan pengawas dinilai penting, karena tingkat kemampuan teknis tim Konsultan Pengawas dapat mengendalikan pelaksanaan proyek sesuai dengan spesifikasi teknis agar dapat memenuhi tingkat layanan seluruh bagian jalan

2. Faktor kesesuaian mekanisme kontrol konsultan pengawas dinilai penting. Tingkat ketepatan mekanisme kontrol konsultan pada setiap lingkup pekerjaan dapat meningkatkan efisien pelaksanaan konstruksi, apabila terdapat pekerjaan yang tidak sesuai, dapat segera diperbaiki dan diselesaikan.

3. Faktor pengalaman Konsultan Pengawas dinilai penting, karena diharapkan semakin banyak proyek konstruksi yang pernah dikerjakan, tingkat pemahaman terhadap ketentuan pelaksanaan proyek semakin baik.

4. Faktor adaptasi Konsultan Pengawas pada perubahan kontrak dinilai penting. Tingkat adaptasi terhadap perubahan kontrak dapat mempengaruhi kecepatan memonitoring 
pelaksanaan pekerjaan sesuai dengan detail pekerjaan sesuai dokumen perubahan kontrak.

5. Faktor pemahaman Konsultan pengawas terhadap teknologi bahan dan peralatan utama dinilai penting, karena tingkat pemahaman dan kompetensi terhadap teknologi bahan dan peralatan utama yang digunakan dapat memperlancar pelaksanaan pekerjaan.

6. Faktor jumlah tenaga ahli Konsultan Pengawas dinilai penting, karena ketepatan jumlah tenaga ahli sesuai dengan lingkup pekerjaan pada kontrak dapat meningkatkan efisien monitoring pekerjaan.

7. Faktor sertifikat keahlian Konsultan Pengawas dinilai penting, karena tingkat ketepatan sertifikat keahlian sesuai dengan bidang pekerjaan yang sedang dikerjakan dinilai semakin mengerti tentang detail pelaksanaan proyek.

Faktor dengan kategori cukup pada pihak Kontraktor merupakan faktor - fakor pada Kontraktor yang dinilai cukup mempengaruhi keberhasilan pelaksanaan kontrak, yaitu :

1. Faktor kebaruan teknologi peralatan utama dinilai cukup, karena kebaruan teknologi diharapkan dapat membantu meningkatkan efisiensi pekerjaan, seperti kapasitas yang lebih besar atau pelaksanaan pekerjaan yang lebih cepat.

\section{KESIMPULAN}

Berdasarkan hasil kuesioner validasi dan filter faktor bagi analisis faktor keberhasilan Preservasi Jalan Skema Long Segment yang telah dilakukan, didapatkan :

- Diperoleh 40 Faktor yang dinilai dapat mempengaruhi keberhasilan pelaksanaan proyek Preservasi Jalan Skema Long Segment.

- Terdapat 15 faktor yang dinilai responden merupakan faktor dengan kategori sangat penting, 24 faktor yang dinilai responden merupakan faktor dengan kategori penting, dan 1 yang dinilai responden merupakan faktor dengen kategori cukup penting.

- Pada kategori sangat penting 7 faktor merupakan faktor dari pihak Kontraktor, 6 faktor merupakan faktor dari pihak PPK, dan 2 faktor merupakan faktor dari pihak Konsultan Pengawas.

- Pada kategori penting 11 faktor merupakan faktor dari pihak Kontraktor, 6 faktor merupakan faktor dari pihak PPK, dan 7 faktor merupakan faktor dari pihak Konsultan Pengawas.

- Pada kategori cukup terdapat 1 faktor dari pihak Konsultan Pengawas.

\section{DAFTAR PUSTAKA}

Budilukito, A. \& Mulyono, A.T. (2016). "Kesiapan Kontraktor Terhadap Kebijakan Preservasi Jalan Nasional Di Sumatera Selatan”. Jurnal HPJI, Vol 2, No 2, Juli 2016, Hal. 133-142.

Direktorat Jenderal Bina Marga (2019). Surat Edaran Direktur Jenderal Bina Marga Nomor 01/SE/Db/2019 tentang Standar Dokumen Pemilihan Pengadaan Jasa Konstruksi Tahun Anggaran 2019 di Lingkungan Direktorat Jenderal Bina Marga. Kementerian Pekerjaan Umum dan Perumahan Rakyat. Jakarta.

Iek, J.P. (2019). "Studi Penerapan Kontrak Long Segment untuk Preservasi Jalan di Kabupaten Sorong Papua Barat". Agregat, Vol. 4, No. 1, Hal. 303-311.

Khaqiqi, M.F.A \& Wulandari, D.A.R. (2019). "Tingkat Pemahaman Pelaksanaan Pekerjaan Konstruksi Preservasi Jalan Berbasis Kontrak Long Segment pada Balai Besar Pelaksanaan Jalan Nasional VIII Surabaya". Narotama Jurnal Teknik Sipil, Vol.3, No. 2, November 2019. 
Suprayitno, H. \& Soemitro, R.A.A (2018). "Preliminary Reflexion on Basic Principle of Infrastructure Asset Management". Jurnal Manajemen Aset Infrastruktur \& Fasilitas, Vol.2, No.1, Maret 2018.

Sita, T. \& Mulyono, A.T. (2016). "Pengaruh Komponen Manajemen Konstruksi Terhadap Capaian Mulu Pemeliharaan Preventif Perkerasan Lentur". Jurnal Transportasi, Vol.16, No. 2, Agustus 2016, hal. 151-162.

Sugiyono (2017). Metode Penelitian Kuantitatif, Kualitatif, dan R\&D. Alfabeta. Bandung.

Suryana (2010). Metodologi Penelitian, Model Praktis Penelitian Kuatitatif dan Kualitatif. Lecture Handouts. Universitas Pendidikan Indonesia. Jakarta.

Suprayitno, H., Soemitro, R.A.A., Maulana, M.A, \& Hesna, Y (2019). "Preliminary Reflection on Performance Indicator and Performance Factor For Infrastructure Asset Management". $6^{\text {th }}$ Andalas Civil Engineering Conference 2019, hal. 44.

Zachawerus, J. \& Soekiman, A. (2018). "Faktor-faktor yang mempengaruhi Kesuksesan Pelaksanaan Proyek Jalan Nasional di Maluku Utara". Jurnal Infrastruktur, Vol.4, No. 01, Juni 2018, Hal. 1-26. 


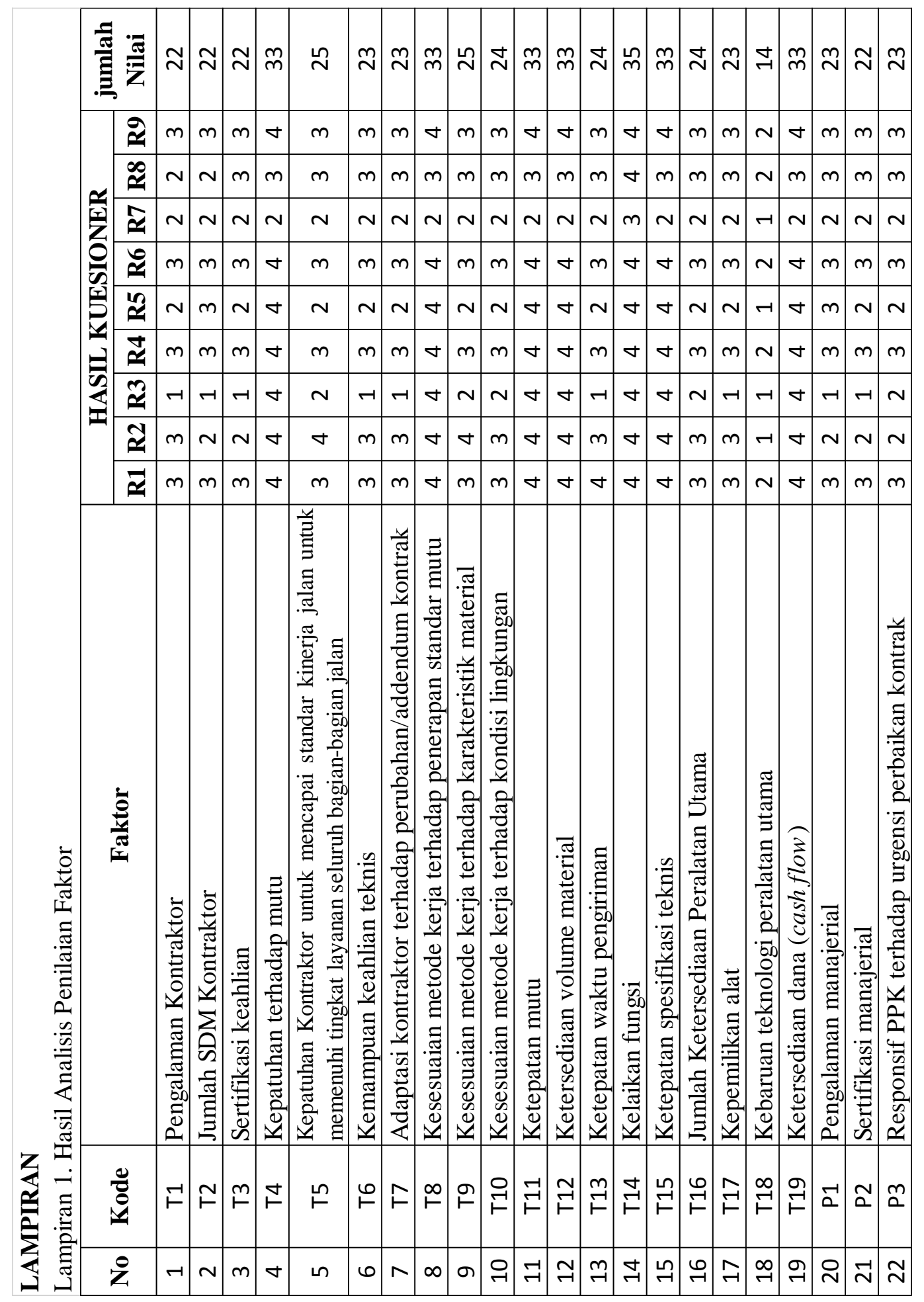




\begin{tabular}{|c|c|c|c|c|c|c|c|c|c|c|c|c|c|c|c|c|c|}
\hline 丞 & $\stackrel{\Perp}{\sim}$ & $m$ & $\stackrel{m}{m}$ & $\lesssim$ & $\stackrel{\bullet}{\sim}$ & m & $m$ & mे & $m$ & $\approx$ & ৯ & $\stackrel{2}{\sim}$ & $\underset{N}{\sim} \stackrel{n}{\sim}$ & $\sqrt[n]{n} \vec{m}$ & $\stackrel{\mathscr{N}}{\sim}$ & $\stackrel{\llcorner}{\sim}$ & $\vec{m}$ \\
\hline$\approx$ & $m$ & $\nabla$ & $\nabla$ & $\nabla$ & $m$ & $\nabla$ & $\nabla$ & $\nabla$ & $\nabla$ & $m$. & \begin{tabular}{l|l}
$\sigma$ & $\theta$
\end{tabular} & $m \mid r$ & $m m$ & $n \mid \nabla$ & $m$ & $m$ & $\nabla$ \\
\hline$\stackrel{\infty}{\mathscr{4}}$ & $\sigma$ & $m$ & $m$ & $m$ & $m$ & $\nabla$ & $m$ & $\nabla$ & $m$ & $m$ & $m / n$ & $m>$ & $v m$ & $n \mid \sigma$ & $m$ & $m$ & $\nabla$ \\
\hline$\underline{\mathbf{z}} \mathbf{z}$ & $r$ & $\sim$ & $\sim$ & $v$ & $\sim$ & $N$ & $N$ & $N$ & $N$ & $N$ & $\sim 1$ & $\sim r$ & $v \sim$ & $v \sim$ & $\sim$ & $N$ & $\sim$ \\
\hline$\stackrel{0}{\infty}$ & 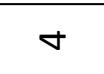 & $\nabla$ & $\nabla$ & $m$ & $m$ & $\nabla$ & $\nabla$ & $\nabla$ & $\nabla$ & $m$ & $m / n$ & $m \mid m$ & $m \pi$ & $n m$ & $m$ & $m$ & $m$ \\
\hline$\stackrel{2}{2}$ & $m$ & $\nabla$ & $\nabla$ & $m$ & $m$ & $\nabla$ & $\nabla$ & $\nabla$ & $\nabla$ & $N$ & $m / r$ & $v e$ & $m \sim$ & $v \mid \nabla$ & $\sim$ & $\sim$ & $\nabla$ \\
\hline 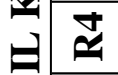 & $m$ & $\nabla$ & $\checkmark$ & $m$ & $m$ & $\nabla$ & $\checkmark$ & $\checkmark$ & $\nabla$ & $m$ & $m / n$ & $m \mid r$ & $m \mid m$ & $n \mid \sigma$ & $m$ & $m$ & $\nabla$ \\
\hline 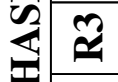 & -1 & $\nabla$ & $\nabla$ & $m$ & $m$ & $\nabla$ & $\nabla$ & $\checkmark$ & $\nabla$ & -10 & $m / r$ & $N$ & $-1-$ & $-1 \sim$ & -1 & $\sim$ & $N$ \\
\hline$\approx$ & $m$ & $\nabla$ & $\nabla$ & $m$ & $m$ & $\nabla$ & $\nabla$ & $\nabla$ & $\nabla$ & $N$ & $m / r$ & $\sim \cap$ & $v m$ & $n \quad \sigma$ & $m$ & $\nabla$ & $\nabla$ \\
\hline$\underline{\approx}$ & $m$ & $\nabla$ & $\sigma$ & $m$ & $m$ & $\nabla$ & $\nabla$ & $\nabla$ & $\nabla$ & $m$ & $m / n$ & $m / n$ & $m \pi$ & $n \mid \sigma$ & $m$ & $m$ & $\nabla$ \\
\hline 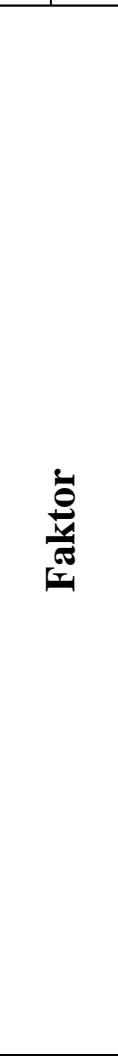 & 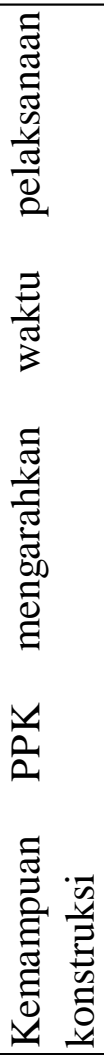 & 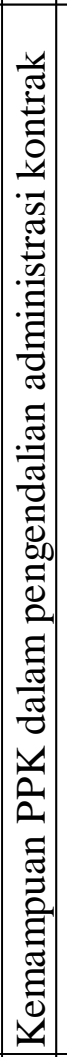 & 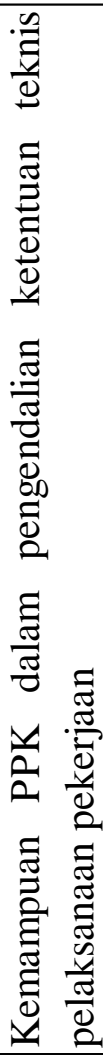 & 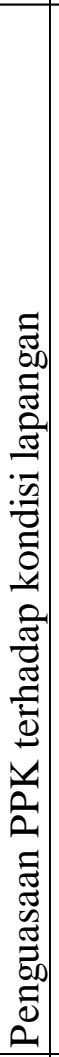 & 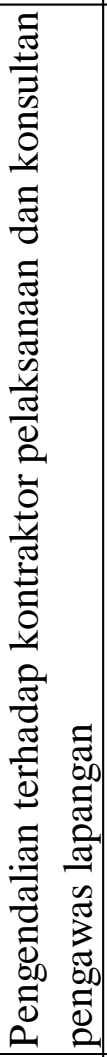 & 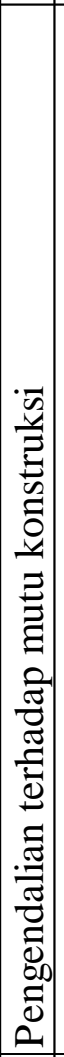 & 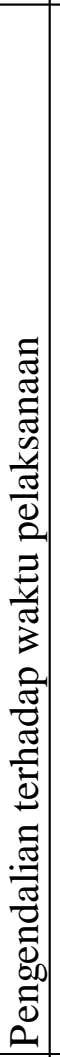 & 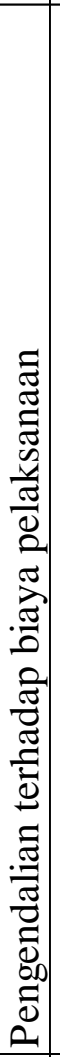 & 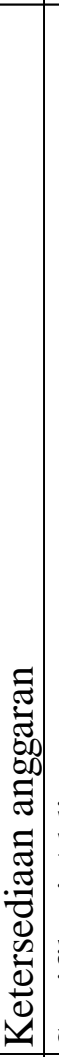 & 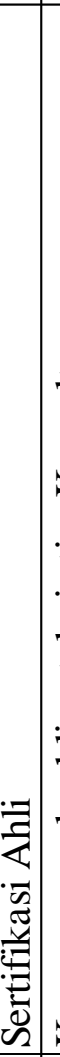 & 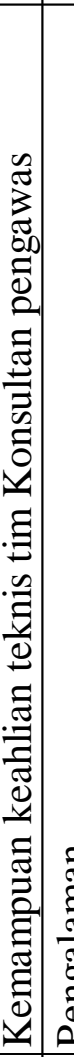 & ב & 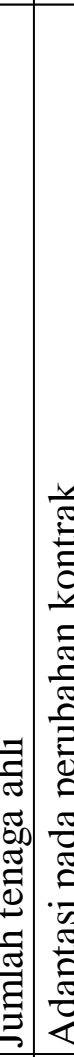 & 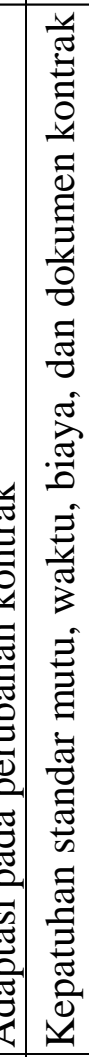 & 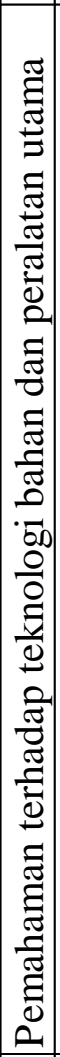 & 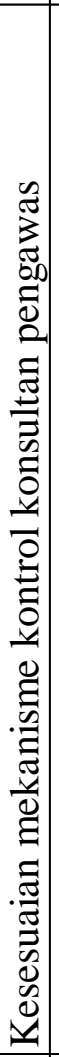 & 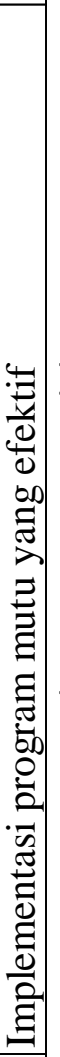 \\
\hline 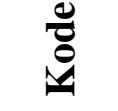 & ¿ & $\stackrel{\llcorner}{\alpha}$ & $\emptyset$ & $\widehat{a}$ & $\infty$ & ฉ & $\begin{array}{l}0 \\
\stackrel{-}{a}\end{array}$ & $\underset{-1}{-1}$ & 곰 & $\vec{\nabla}$ & 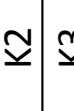 & $\underline{m}$ & $\nabla \underline{v}$ & 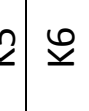 & $\underline{\underline{a}}$ & $\underset{⿱}{\infty}$ & 穴 \\
\hline z & $\stackrel{n}{\sim}$ & $\underset{\sim}{\sim}$ & $\stackrel{\Perp}{\sim}$ & $\stackrel{\bullet}{\sim}$ & స & $\stackrel{\infty}{\sim}$ & શิ & 이 & $\vec{m}$ & $\tilde{m}$ & 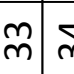 & ১) & \begin{tabular}{l|l}
$\tilde{m}$ & $\mathscr{m}$
\end{tabular} & $\begin{array}{l}n \\
n\end{array}$ & $\stackrel{\infty}{m}$ & ஜ & 우 \\
\hline
\end{tabular}


(e)ISSN 2615-1847 (p)ISSN 2615-1839

Jurnal Manajemen Aset Infrastruktur \& Fasilitas - Vol. 4, No. 2, April 2020 